\title{
Analysis of a hydrated silicate of alumina
}

\section{Damour \& Salvetat}

To cite this article: MM. Damour \& Salvetat (1848) Analysis of a hydrated silicate of alumina, Philosophical Magazine Series 3, 32:213, 149-151, DOI: 10.1080/14786444808645946

To link to this article: http://dx.doi.org/10.1080/14786444808645946

册 Published online: 30 Apr 2009.

Submit your article to this journal $\pi$

Џll Article views: 3

Q View related articles $\asymp$

4 Citing articles: 1 View citing articles 


\section{$\left[\begin{array}{lll}149 & ]\end{array}\right.$}

\section{Intelligence and Miscellaneous Articles.}

\section{ANALYSIS OF A HYDRATED SILICATE OF ALUMINA. BY MM. DAMOUR AND SALVETAT.}

$\mathbf{T}$

HIS mineral is found in the environs of Montmorillon (Vienne). It occurs in cavities in a brownish argil ; it is very soft and saponaceous to the feel, perfectly amorphous, and may be readily broken down between the fingers; its colour is bright rose-red. Without possessing the plastic properties of clay, it very readily diffuses through water; it is infusible by the blowpipe; it is also infusible in the high temperature of a porcelain furnace, but assumes the whiteness and appearance of biscuit, and is hard enough to scratch glass.

When heated in a tube, it yields much water, loses its rose colour, and becomes grayish-white; from $60^{\circ} \mathrm{F}$. and upwards it loses water gradually, and when heated to $212^{\circ}$, it still obstinately retains 0.1512 of combined water. With microcosmic salt it partially dissolves, and leaves a bulky skeleton of silica; solution of caustic soda separates from it a small portion of gelatinous silica.

Hydrochloric acid partially attacks it, without producing the slightest effervescence, and dissolves some lime, magnesia, potash, alumina, oxide of iron, and traces of manganese; the greater part of the mineral remains insoluble, and retains its rose colour. If, after this treatment with acid, the insoluble portion be boiled in a solution of caustic soda, a considerable quantity of silica is dissolved; the insoluble portion being again treated with hydrochloric acid, it is completely decomposed; the silica separates in a flocculent state, and the solution contains the rest of the alumina.

Sulphuric acid, when heated till it begins to vaporize, completely decomposes the mineral, within about one-hundredth; on pouring water on the substance thus acted upon, the alkali and the other bases are dissolved, and pure silica is deposited. The solution, separated from the silica, gives with ammonia a precipitate coloured with a little oxide of iron; the solution, separated from the alumina, is rendered turbid by oxalate of ammonia, and phosphate of soda afterwards produces an appreciable degree of turbidness.

Examination showed that the mineral contained no sulphuric acid; and the various tests indicated that the mineral is essentially composed of silica, alumina and water, and also contained small quantities of lime, magnesia, potash, oxide of iron, and manganese ; the peculiar rose colour appeared to be owing to combustible matter.

The different analyses of this mineral were performed by various processes; and in all of them at least one gramme was used.

A. The mineral was fused with four times its weight of very dry carbonate of soda; the residue was treated with water and hydrochloric acid; the silica was separated by evaporation twice to dryness; heated to redness and weighed, it was totally soluble in a solution of caustic soda.

The solution, separated from the silica, was precipitated by ammonia, and suffered to remain at rest during twenty-four hours. The 
deposit of alumina and peroxide of iron was redissolved on the filter by dilute hydrochloric acid.

The solution was supersaturated with soda, which redissolved the alumina, and left the peroxide of iron with a small quantity of lime and magnesia, which the alumina had taken down with it. These matters were redissolved in hydrochloric acid, and the oxide of iron precipitated by ammonia, the filtered liquor being added to that which contained the greater part of the lime and magnesia.

The alkaline solution of alumina was decomposed by hydrochloric acid, and this last separated by hydrosulphate of ammonia; the peroxide of iron was dried and weighed; it dissolved totally in boiling hydrochloric acid.

Lastly, the lime and magnesia were successively precipitated by oxalate and phosphate of ammonia; the ammoniaco-magnesian phosphate was washed with slightly ammoniacal water.

B. The decomposition of the mineral by means of hydrofluoric acid, admitted readily of ascertaining the quantity of alkalies which it contained. The operation was performed in a platina crucible, and the solution evaporated to dryness with sulphuric acid; the residue was treated with water, the solution was filtered, the oxide of iron and alumina separated by ammonia, and the lime then thrown down by oxalate of ammonia.

The liquor filtered after the separation of the lime was evaporated to dryness, and the residue, heated to redness, consisted of alkaline sulphates, mixed with sulphate of magnesia; the sulphates were dissolved in water and precipitated by acetate of barytes; the solution was filtered, evaporated to dryness, and calcined to decompose the acetates and convert them into carbonates; these were treated with water; the alkaline carbonates dissolved, and the magnesia remained insoluble with the carbonate of barytes.

The alkaline carbonates were converted into chlorides and weighed, the potash precipitated by chloride of platina. 'The magnesia was separated by sulphuric acid from the carbonate of barytes, with which it was mixed, and estimated in the state of sulphate.

C. The employment of excess of boiling sulphuric acid and evaporation to dryness, is a very simple method of analysing minerals of this description. The substance decomposed by this method was treated with water; the deposit separated by filtration, and which consisted of silica, readily dissolved in excess of caustic soda, except a minute quantity of sand, which did not amount to more than 0.0140 of the weight of the substance submitted to analysis. The alkaline liquid, saturated by an acid, gave pure silica, which was separated by the usual processes, after the evaporation to dryness had been twice repeated.

The mean of four analyses performed by M. Salvetat (1.), and of three by M. Damour (II.), gave the following results :- 
I.

\begin{tabular}{|c|c|c|}
\hline Silica & $49 \cdot 40$ & 50.04 \\
\hline Alumina & $19 \cdot 70$ & $20 \cdot 16$ \\
\hline Peroxide of iron $\ldots$. & $\cdot 80$ & $\cdot 68$ \\
\hline Lime. . . . . . . . & $1 \cdot 50$ & $\mathrm{I} \cdot 46$ \\
\hline Potash $\ldots \ldots \ldots \ldots$ & $1 \cdot 50$ & $1 \cdot 27$ \\
\hline Soda............ & traces & \\
\hline Magnesia . . . . . . . & $\cdot 27$ & $\cdot 23$ \\
\hline Oxide of manganese & traces & traces \\
\hline Water $\ldots \ldots \ldots \ldots$ & $25 \cdot 67$ & 2600 \\
\hline & $8 \cdot 84$ & $99 \cdot 84$ \\
\hline
\end{tabular}

II. 0.04

$99 \cdot 84$

Ann. de. Ch. et de Phys., Novembre 1847.

\section{ON 'IHE ACTION OF CHLORINE ON BENZOATE OF POTASH. BY M. SAINT-EVRE,}

When a continuous current of chlorine is passed into a solution of benzoate of potash rendered strongly alkaline, there is produced, after the lapse of some time, an abundant disengagement of carbonic acid ; and chloride of potassium is also formed. The character of this reaction is, then, a combustion of a part of the carbon of the benzoic acid, and consequently a substance must be formed, the molecule of which is more simple. Analysis fully confirms this conclusion. The new substance is an acid which is precipitated in the state of a potash salt; this salt purified, and then decomposed by sulphuric acid, yields the acid in question; this last, in its turn, after purification by several crystallizations, constitutes a volatile substance fusible at $176^{\circ}$ to $181^{\circ} \mathrm{F}$. Its analysis by the salt of silver yielded numbers which indicated the formula $\mathrm{C}^{24} \mathrm{H}^{10} \mathrm{Cl}^{2} \mathrm{O}^{4}$.

Subtracting the chlorine and going back to the primary substance, it will be seen that it differs from the hydrate of phenyle of M. Laurent only by the fixation of two molecules of oxygen, and it is well known that this is the relation of an acid to aldehyde which corresponds to it. The author therefore proposes provisionally to call the new substance monochloruretted phenylic acid. If we had phenylic acid $\mathrm{C}^{34} \mathrm{H}^{19} \mathrm{O}^{4}$, the hydrocarburet formed at a high temperature in presence of the caustic alkalies, would be necessarily phenylen $\mathrm{C}^{20} \mathrm{H}^{12}$. This last, in its turn, treated with fuming nitric acid, would yield the nitrogenous body $\mathrm{C}^{20}\left(\begin{array}{l}\mathrm{H}^{10} \\ \mathrm{~N}^{2} \mathrm{O}^{4}\end{array}\right)$. Lastly, this dissolved in ammoniated alcohol, and submitted to the action of a current of sulphuretted hydrogen, as happily suggested by $M$. Zinin, ought to yield, by the fixation of hydrogen, the body $\mathrm{C}^{20} \mathrm{H}^{14} \mathrm{~N}^{2}$, that is to say, nicotina.

This is exactly what happens in the present case; except that instead of having the preceding bodies, a parallel series is obtained, in which one equivalent of chlorine is substituted for one equivalent of hydrogen.

The author has successively obtained the substances represented 